\title{
Saving Lives Through Better Design Standards
}

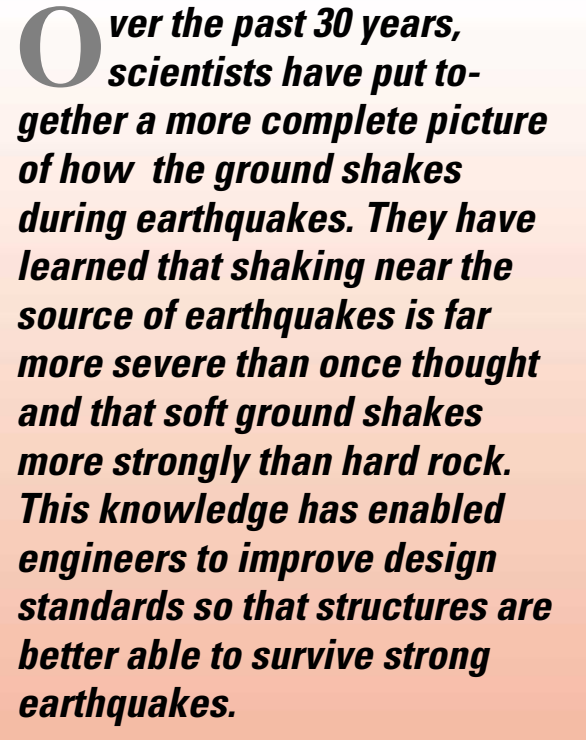

When the 1989 Loma Prieta earthquake struck, 42 people tragically lost their lives in the collapse of a half-mile-long section of the Cypress structure, an elevated double-decker freeway in Oakland, California. Yet adjacent parts of this structure withstood the magnitude 6.9 temblorwhy? The part that collapsed was built on man-made fill over soft mud, whereas adjacent sections stood on older, firmer sand and gravel deposits. Following the collapse, scientists set out instruments in the area to record the earthquake's many strong aftershocks. These instruments showed that the softer ground shook more forcefully than the firmer material-even twice as violently.

The collapse of the Cypress freeway, built in the 1950's, emphasized the importance of having accurate knowledge of the destructive forces a structure may face. Before 1932, the strength of ground shaking near large earthquakes had not been recorded. At that time, seismographs were used primarily to record weak motions from distant earthquakes and were overloaded by the intense shaking of large, nearby shocks. In 1932, scientists began to install special instruments to accurately record strong shaking in earthquake-prone regions of the United States. In the 1960's,

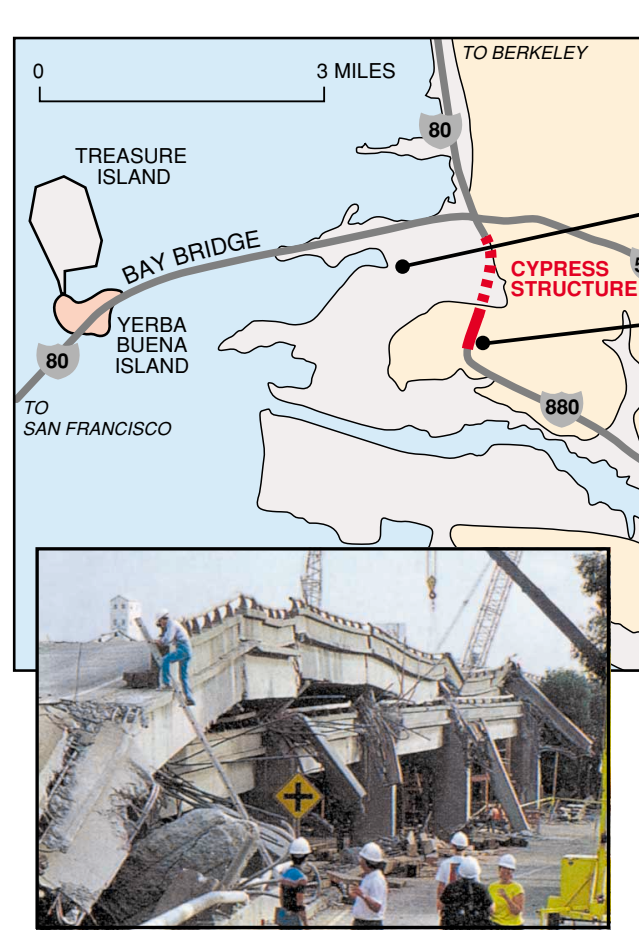

the number of these instruments totaled only about 100 , but it has now grown to more than 3,000. The vast majority are operated by the United States Geological Survey (USGS) and the California Division of Mines and Geology. This expanding network of instruments is yielding large numbers of strong-motion records. The records provide an ever more complete picture of how strong and how varied shaking can be in a large earthquake.

One important fact to emerge from the growing body of strong-motion records is that shaking close to an earthquake's source is much more forceful than once thought. As recently as the late 1960's, the prevailing view was that shaking would not exceed about $1 / 2 \boldsymbol{g}$ ( $\boldsymbol{g}$ is the acceleration of a falling object due to gravity). Recordings from the 1971 San Fernando, California, earthquake suggested that this limit was too low. Data from more recent earthquakes conclusively demonstrate that shaking within 10 to 15 miles of a magnitude 7 shock commonly exceeds $1 / 2 \boldsymbol{g}$ and may top $1 \boldsymbol{g}$.

Although shaking has now been recorded at many sites near earthquakes as large as magnitude 7.3, there are still no close-in records from temblors comparable to the largest historical shocks, such as the magnitude 8 earthquake of 1811 in the central Mississippi Valley and the magnitude

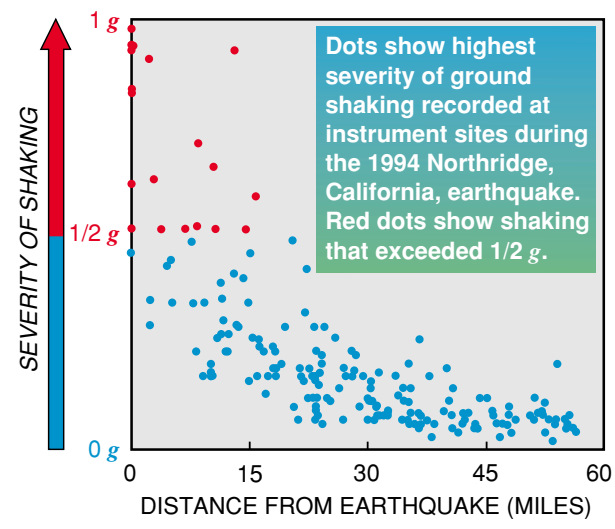

As recently as the late 1960's, earthquake shaking severity was not thought to exceed a maximum of about $1 / 2 \mathrm{~g}$ ( $\mathrm{g}$ is the acceleration of a falling object due to gravity). During the 1994 Northridge, California, earthquake (magnitude 6.7), however, many instruments within about 15 miles of the shock recorded ground shaking that exceeded $1 / 2 \mathrm{~g}$ (red dots). This new information has already led to proposed increases in building-code strength requirements for structures built near potential earthquake sources. 
9.2 Alaska earthquake of 1964. Shaking near the centers of such major earthquakes likely exceeds the levels recorded in magnitude 7 shocks.

In addition to improving our knowledge of the severity of close-in ground shaking, the network of strong-motion instruments has also improved our understanding of why the intensity of shaking varies locally so dramatically. Until 1957, scientists had never accurately measured how different ground types affect the local intensity of earthquake shaking, although they had long noticed that structures built on soft soil were more severely damaged in earthquakes than those built on firm soil or bedrock. The records of ground motion obtained during the 1989 Loma Prieta earthquake and its aftershocks vividly confirmed that soft clay soil shakes more violently than firmer sandy soil, which in turn shakes much more than hard rock. The collapse of the part of the Cypress structure that stood on soft soil was clearly due to the stronger shaking of that ground type.

Building codes are the public's first line of defense against earthquakes. The codes specify the levels of earthquake forces that structures must be designed to withstand. These specifications are based on current information from strong-motion instruments. As ground motions of greater intensity have been recorded, the minimum earthquake requirements specified in building codes have been raised. In addition, provisions for different soil conditions have been added to the codes as scientists have documented the significant influence of soil type on shaking intensity. In recent earthquakes, buildings built to modern codes have generally sustained relatively little damage.

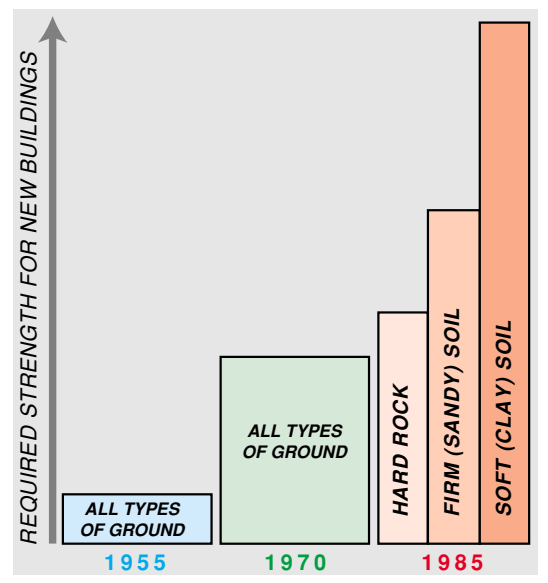

Earthquake requirements in building codes have increased over time as scientists and engineers have obtained new information. Note that recent requirements specify separate criteria for different ground types.

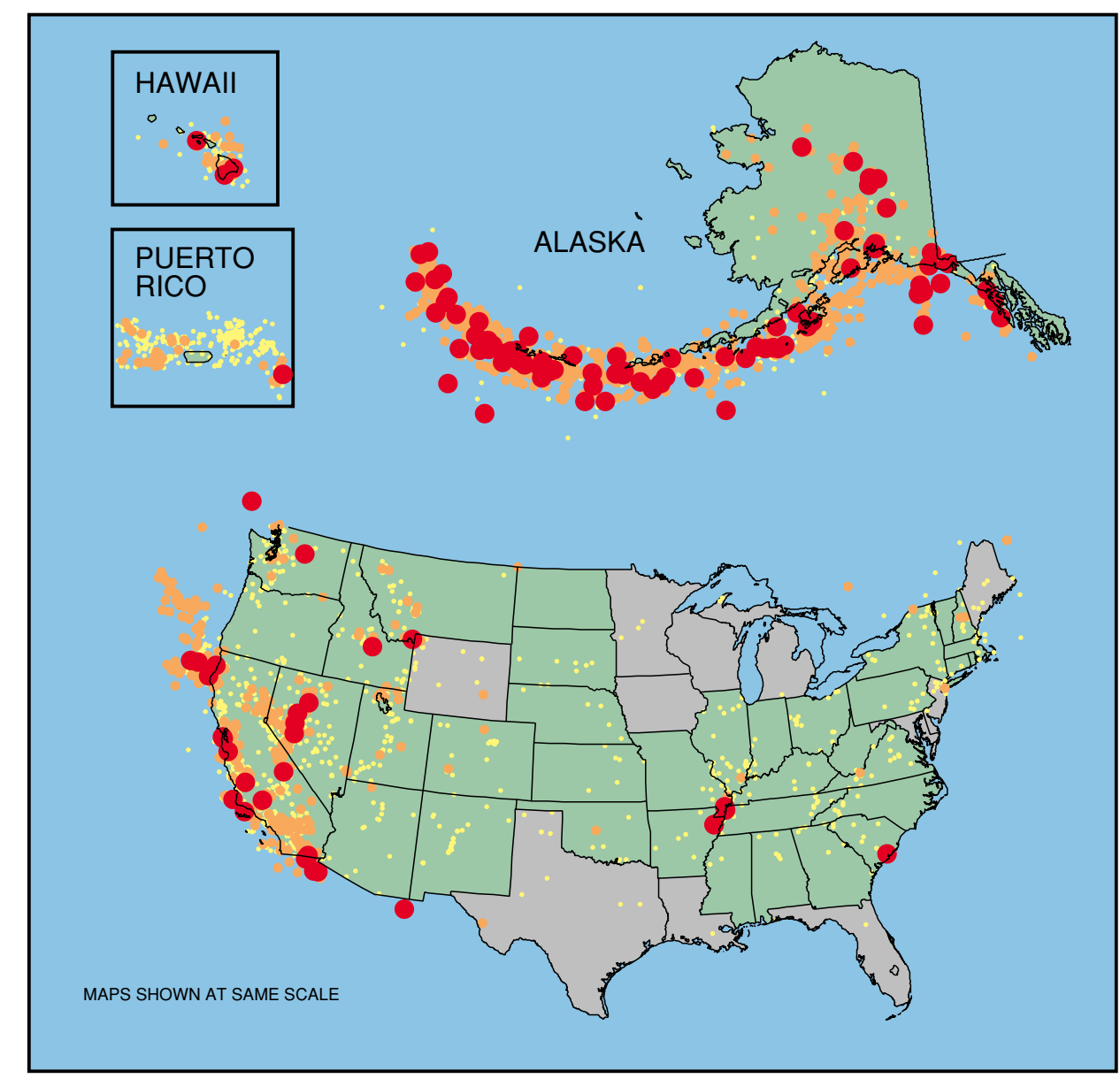

The U.S. Geological Survey has strong-motion instruments in many states (green), covering most of the earthquake-prone areas of the United States. Colors show magnitudes of historical earthquakes: red, 7 or greater; orange, 5.5 to 7 ; yellow, 4.5 to 5.5 .

Many cities around the United States, including Boston, Massachusetts, Memphis, Tennessee, and Salt Lake City, Utah, now require that new construction meet modern seismic standards. Structures built to these standards are much safer in earthquakes than structures built 50 or even 25 years ago. Nonetheless, it will still be necessary to refine the earthquake requirements in building codes in the future. Each major earthquake produces new strong-motion records that expand our knowledge of ground shaking. For example, observations from the devastating 1994 Northridge, California, earthquake and other recent temblors led engineers to propose increases in the seismic standards for structures built near dangerous faults.

Strong-motion data collected by the USGS have contributed to the improvement of building codes over the decades. These improved codes have saved many lives and reduced damage in recent earthquakes. A growing network of instruments will provide even more extensive data in earthquakes to come. Using this information, scientists and engineers will be able to sug- gest further improvements to building codes. These improvements will help protect citizens of the United States from loss of life and property in future earthquakes.

Mehmet Çelebi, Paul A. Spudich, Robert A. Page, and Peter H. Stauffer Graphic design by Susan Mayfield and Sara Boore

COOPERATING ORGANIZATIONS

California Division of Mines and Geology California Institute of Technology Columbia University

Pacific Gas and Electric Company University of Puerto Rico, Mayaguez

U.S. Army Corps of Engineers

U.S. Bureau of Reclamation

U.S. Department of Energy

U.S. Department of Veterans Affairs

Many smaller agencies

Private building owners

For more information contact: Earthquake Information Hotline (650) 329-4085 U.S. Geological Survey, Mail Stop 977 345 Middlefield Road, Menlo Park, CA 94025 http://quake.usgs.gov/

This Fact Sheet and any updates to it are available online at:

http://pubs.usgs.gov/fs/1995/fs176-95/ 